\title{
APLICACIÓN DEL NANOCOMPOSITO ARCILLA - CARBOXIMETILQUITOSANO - NANOPARTÍCULAS DE PLATA EN FILTROS PARA EL TRATAMIENTO DE AGUAS DE CONSUMO DE ZONAS RURALES DE CAMANÁ, AREQUIPA
}

\author{
María Elena Talavera Núñez ${ }^{a^{*}}$, Irene Zea Apaza ${ }^{a}$, Corina Vera Gonzales ${ }^{\mathrm{a}}$, \\ Julia Zea Álvarez ${ }^{a}$, Luis Rodrigo Benavente Talavera ${ }^{a}$
}

\begin{abstract}
RESUMEN
Se formuló un filtro con un nanocompósito de arcilla-carboximetilquitosano-nanopartículas de plata, que se usó para eliminar bacterias y aniones en aguas de consumo humano.

Las nanopartículas de plata se obtuvieron por reducción del nitrato de plata $1 \mathrm{mM}$, con carboximetilquitosano al $0,01 \%$ y borohidruro de sodio $2 \mathrm{mM}$ como iniciador de la reducción. Posteriormente, se obtuvo los filtros como recipientes con arcilla y aserrín de madera como formador de poros, en la proporción de 2:1; se moldeó, secó y sinterizó a $800^{\circ} \mathrm{C}$ por tres horas. Seguidamente, los filtros se impregnaron con la dispersión coloidal de carboximetilquitosano-nanopartículas de plata, por inmersión durante 12 horas.

Se definieron cuatro puntos de muestreo del agua: Huacapuy, La Punta, Plaza de Quilca, Caleta de Quilca. Al evaluar la capacidad filtrante de los filtros, se encontró que se remueven: conductividad 84,03 \% en La Plaza de Quilca, sulfatos 85,48 \% en La Plaza de Quilca; cloruros 93,93 \% en La Plaza de Quilca. Por otro lado, las bacterias coliformes fecales y coliformes totales se removieron en un 100 \% en La Punta y en la Plaza de Quilca. No se encontraron bacterias coliformes en Huacapuy ni en la Caleta de Quilca. Por lo que se puede confirmar que los resultados tienen un porcentaje de remoción significativo en la eliminación de aniones, en cuanto a bacterias coliformes totales y coliformes fecales se removieron en su totalidad.
\end{abstract}

Palabras clave: arcilla, filtro, carboximetilquitosano, nanopartículas de plata, nanocompósito.

a Universidad Nacional San Agustín de Arequipa. Facultad de Ciencias Naturales y Formales, Departamento Académico de Química. mtalaveran@unsa.edu.pe 


\title{
APPLICATION OF NANOCOMPOSITOS CLAY -CARBOXIMETHYLQUITOSAN - NANOPARTICLES OF SILVER IN FILTERS FOR THE TREATMENT OF WATER OF RURAL AREAS OF CAMANA, AREQUIPA
}

\begin{abstract}
A filter made of a nanocomposite of clay - carboximethylchitosan - silver nanoparticles was created to eliminate bacteria and anions in water for human consumption.

The silver nanoparticles were obtained by reduction of silver nitrate $1 \mathrm{mM}$, with carboximethyl chitosan at $0.01 \%$ and sodium borohydrido $2 \mathrm{mM}$ as starter of the reduction. Then the clay filters were made with wood sawdust as the pore maker in a 2:1 proportion; it was molded, dried and sinterized at $800^{\circ} \mathrm{C}$ for 3 hours. Quickly the filters were impregnated with the colloidal dispersion of carboximethyl chitosan - silver nanoparticles by immersion for 12 hours.

Four water sampling points were defined: Huacapuy, La Punta, Plaza de Quilca, Caleta de Quilca. When evaluating the filtering capacity of the filters, it was found that the following were removed: conductivity $84.03 \%$ in La Plaza de Quilca, sulfates $85.48 \%$ in La Plaza de Quilca; 93.93\% chlorides in La Plaza de Quilca. On the other hand, fecal coliform bacteria and total coliforms were removed $100 \%$ at La Punta and Plaza de Quilca. No coliform bacteria were found in Huacapuy or in the Caleta de Quilca. So it can be confirmed that the results have a significant removal percentage in the elimination of anions, in terms of total coliform bacteria and fecal coliforms were removed in its entirety.
\end{abstract}

Key words: clay, filter, carboximethyl chitosan, silver nanoparticles, nanocomposite.

\section{INTRODUCCIÓN}

La nanotecnología es el estudio, diseño, creación, síntesis, manipulación y aplicación de materiales, aparatos y sistemas funcionales a través del control de la materia a nanoescala, y la explotación de fenómenos y propiedades de la materia a nanoescala, a esta escala los átomos y moléculas, muestran fenómenos y propiedades totalmente nuevas. Por lo tanto, científicos utilizan la nanotecnología para diseñar materiales novedosos y poco costosos con propiedades únicas ${ }^{1}$.

Estos fenómenos se rigen bajo las leyes de la termodinámica coloidal y sus propiedades están entre los fenómenos mecánico cuánticos y los mecánico clásicos, estas nuevas propiedades son las que los científicos aprovechan para sintetizar nuevos materiales (nanomateriales) o dispositivos nanotecnológicos, de esta forma la Nanotecnología promete soluciones a múltiples problemas que enfrenta actualmente la humanidad como: ambientales, energéticos, de salud (nano medicina), y muchos otros; sin embargo, estas nuevas tecnologías pueden conllevar a riesgos y peligros si son mal utilizadas ${ }^{2}$. 
Los nanomateriales son una nueva clase de materiales, ya sean cerámicos, metales, semiconductores, polímeros o una combinación de estos o nanocompósitos, en los cuales, por lo menos uno de sus componentes, tiene una de sus dimensiones entre 1 y $100 \mathrm{~nm}$; representan una transición entre moléculas, átomos y un material con dimensiones de sólido volumétrico. Debido a su tamaño reducido a nanómetros, las propiedades fisicoquímicas difieren del mismo material, de las moléculas y los átomos ${ }^{3}$.

El tratamiento de agua para consumo es una opción viable para mejorar y asegurar la calidad del agua, principalmente en lugares que no cuentan con sistemas de tratamiento, o los sistemas existentes operan de manera deficiente o existen condiciones de sequía, en el estudio comparativo de dos sistemas de filtración para agua de consumo casero ${ }^{4}$, se evaluaron dos sistemas: un filtro de 1 vela (1VC) y otro de 2 velas cerámicas (2VC) durante seis meses. Se evaluó la eficiencia de reducción de turbiedad y E. coli. Se empleó un sustrato sintético

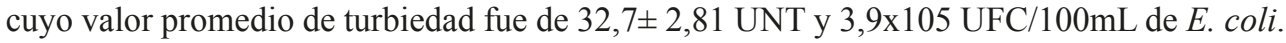
Los resultados mostraron que ambos sistemas de filtración lograron reducir la turbiedad a valores promedio de 0,28 UNT (99\% de eficiencia) y eliminar E. coli entre 99,99 y $100 \%$. No se encontraron diferencias estadísticas significativas en términos de la calidad de agua filtrada por ambos sistemas.

Se aplica un método convencional para producir cerámicos porosos, por adición y pirolisis de un material orgánico: el almidón, que actúa como formador de poros. Las suspensiones acuosas de (52-55 V\%) de la mezcla zirconio, se estabilizaron con una solución de poliacrilato de amonio comercial como dispersante y se consolidaron en moldes de plástico a $90^{\circ} \mathrm{C}$ por 30 minutos. Luego se sinterizaron entre $1000-1500^{\circ} \mathrm{C}$ por $2 \mathrm{~h}$. Las características del producto se evaluaron por medidas de densidad, contracción volumétrica, intrusión de mercurio y la evolución de las fases cristalinas por difracción de rayos X (DRX) y microscopía electrónica de barrido (SEM). Se encontró que las propiedades microestructurales del cerámico (volumen de poros, relación entre porosidad abierta y cerrada, distribución de tamaño, morfología de los poros) dependen de la cantidad de almidón adicionado y de la temperatura de sinterización ${ }^{5}$.

\section{PARTE EXPERIMENTAL}

El desarrollo experimental se realizó en los Laboratorios del Departamento Académico de Química de la Universidad Nacional San Agustín de Arequipa.

Las muestras de arcilla, usadas como matriz del nanocompósito, fueron muestreadas en el distrito de Yarabamba, que se encuentra situado al suroeste de la ciudad de Arequipa, cuyas coordenadas son: Latitud: -16.5481, Longitud: -71.4775 ; $16^{\circ} 32^{\prime} 53^{\prime \prime}$ Sur, 71 ${ }^{\circ} 28^{\prime} 39^{\prime \prime}$ Oeste, se dispusieron en bolsas de plástico herméticas y fueron transportadas al laboratorio para su caracterización. En cuanto a la estructura y composición de la arcilla, se realizó por técnicas de microscopía electrónica de barrido (SEM - EDX), en la caracterización fisicoquímica se determinaron los siguientes parámetros: $\mathrm{pH}$, sales solubles, bases intercambiables, capacidad de intercambio de cationes (CIC) y densidad absoluta ${ }^{6}$. 
La obtención de nanopartículas de plata fue por reducción química de nitrato de plata con carboximetilquitosano utilizando borohidruro de sodio $2 \mathrm{mM}$ como iniciador de la reducción; la evaluación del plasmón de las nanopartículas de plata se realizó por espectroscopia UVvisible y dispersión de luz dinámica (DLS)7.

Los filtros se obtuvieron haciendo una mezcla de arcilla-aserrín (como formador de poros, en la proporción de 2:1) y agua para formar una pasta, se moldeó, se secó y se llevó a sinterización a $800^{\circ} \mathrm{C}$ por tres horas. Posteriormente, los filtros se trataron por el método de inmersión en la dispersión coloidal de nanopartículas de plata-carboximetilquitosano por 12 horas, se secaron y con estos filtros se realizaron las pruebas del agua en estudio ${ }^{10}$.

En el agua de consumo humano, se midieron las siguientes variables: $\mathrm{pH}$, conductividad, turbiedad, cloruros, sulfatos, fluoruros, nitratos, nitritos, fosfatos y recuento de microorganismos; numeración de coliformes totales, numeración de coliformes fecales (NMP), por los métodos de la AWWA, antes y después del filtrado8 y de esta forma se determinó la eficacia del filtro. Los puntos de muestreo del agua fueron: Huacapuy, La Punta, Plaza de Quilca, Caleta de Quilca, situados en Camaná ubicada en la parte sur occidental de Arequipa, cuyas coordenadas son: Latitud: -16.6238, Longitud: -72.7105; $16^{\circ} 37^{\prime} 26^{\prime \prime}$ Sur, $72^{\circ} 42^{\prime} 38^{\prime \prime}$ Oeste. Las pruebas se realizaron con el agua antes de filtrar, con el agua pasada por el filtro impregnado con la dispersión coloidal del nanocompósito: carboximetilquitosano-nanopartículas de plata. En la figura $\mathrm{N}^{\circ} 1$ se observa el diagrama de bloques de proceso de obtención y funcionamiento de los filtros con el nanocomposito arcilla- carboximetilquitosano-nanopartículas de plata. 


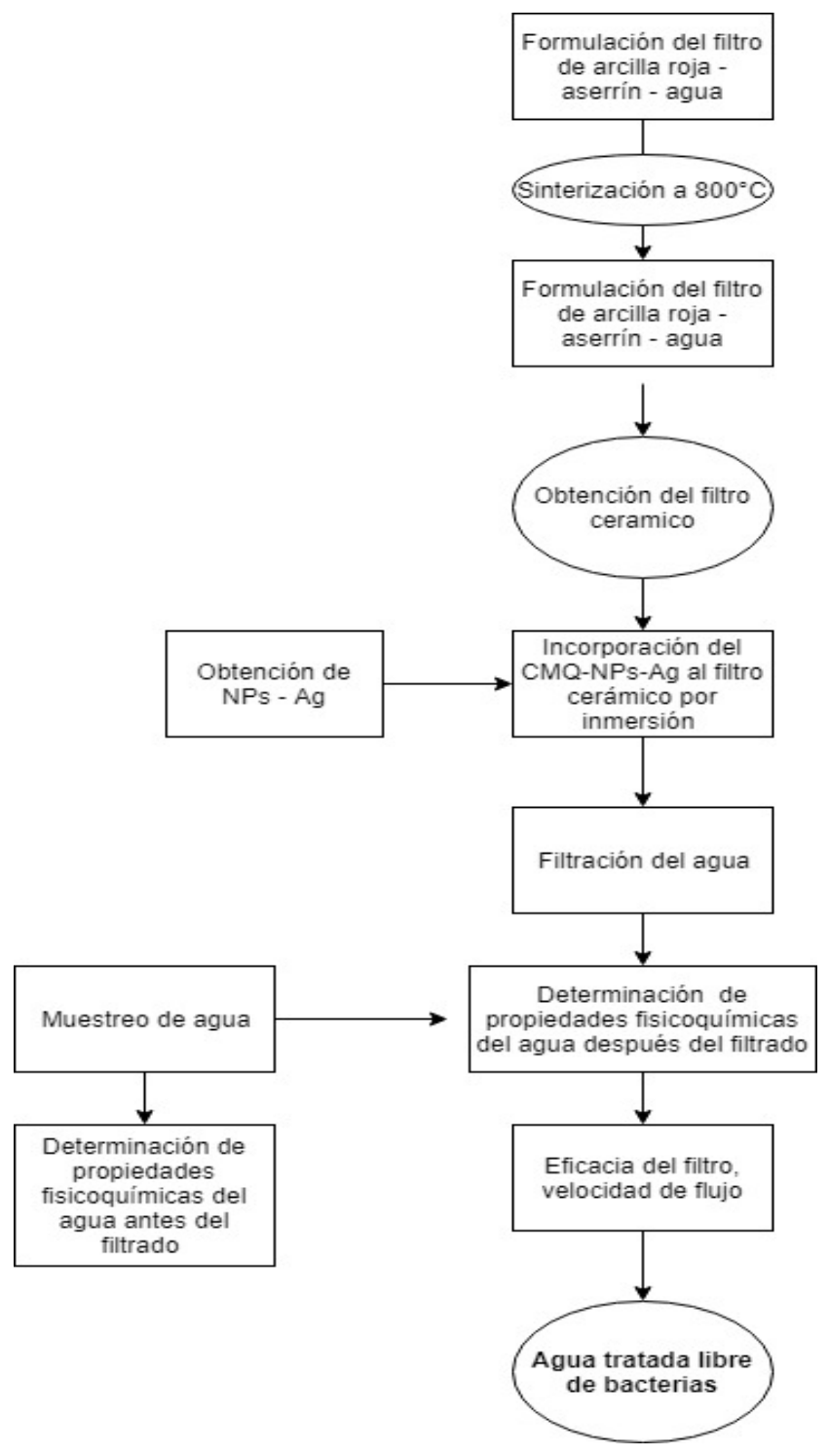

Fuente: Elaboración propia

Figura 1. Diagrama de bloques de la obtención y funcionamiento del filtro con el nanocomposito arcilla- carboximetilquitosano-nanopartículas de plata. 


\section{RESULTADOS Y DISCUSIÓN}

\section{Síntesis de nanopartículas de plata:}

La síntesis se hizo por reducción química del nitrato de plata $1 \mathrm{mM} 9$ con carboximetilquitosano y borohidruro de sodio $2 \mathrm{mM}$ como precursor de la reacción, de acuerdo a la siguiente ecuación:

$$
4 \mathrm{AgNO}_{3}+\mathrm{NaBH}_{4}+3 \mathrm{H}_{2} \mathrm{O} \rightarrow 4 \mathrm{Ag}+\mathrm{H}_{3} \mathrm{BO}_{3}+3 \mathrm{HNO}_{3}+\mathrm{NaNO}_{3}+2 \mathrm{H}_{2}
$$

Al realizar la síntesis se observó una solución de color amarillo por la resonancia del plasmón de las nanopartículas de plata, lo que indica su presencia.

\section{Evaluación de las nanopartículas de plata por espectroscopia UV-visible}

Al caracterizar las nanopartículas por UV-visible, se encontró que el máximo de absorbancia se encuentra entre $410 \mathrm{~nm}$ y $420 \mathrm{~nm}$, lo que es una característica de la presencia de nanopartículas esféricas de plata. Metales como la plata, que posee electrones libres, muestra un plasmón de resonancia en el espectro visible, dando lugar a colores no observados en los mismos materiales a escala macrométrica ${ }^{11}$. Por ejemplo, las nanopartículas de plata muestran una intensa SPR (resonancia de plasmones superficiales) principalmente en los intervalos de longitud de onda de 410-420 nm, como se observa en la figura 2:

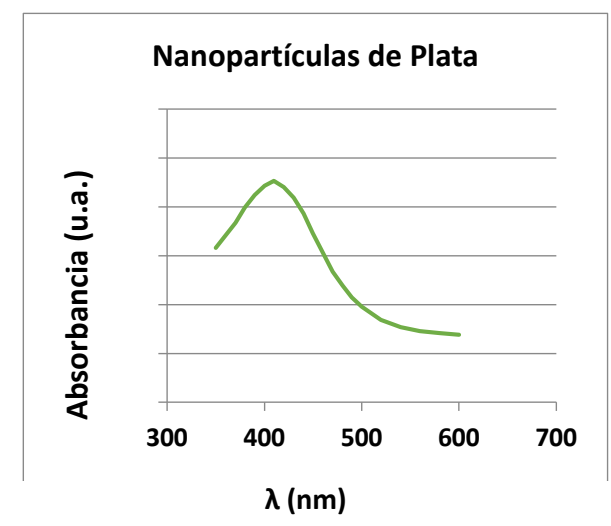

Fuente: Elaboración propia

Figura 2. Espectro UV-visible de las nanopartículas de plata

Se observa un máximo de absorbancia entre $410 \mathrm{~nm}$ y $420 \mathrm{~nm}$, lo que es una característica de la presencia de nanopartículas de plata, por la resonancia de plasmones superficiales.

\section{Evaluación del tamaño las nanopartículas de plata por dispersión de luz dinámica (DLS)}

En la evaluación por dispersión de luz dinámica(DLS), se determinó el diámetro hidrodinámico de las nanopartículas de plata, en los histogramas de distribución, se encuentran tamaños de $2,716 \mathrm{~nm}, 11,05$ y $67,63 \mathrm{~nm}$; lo que se observa en la figura 3 : 


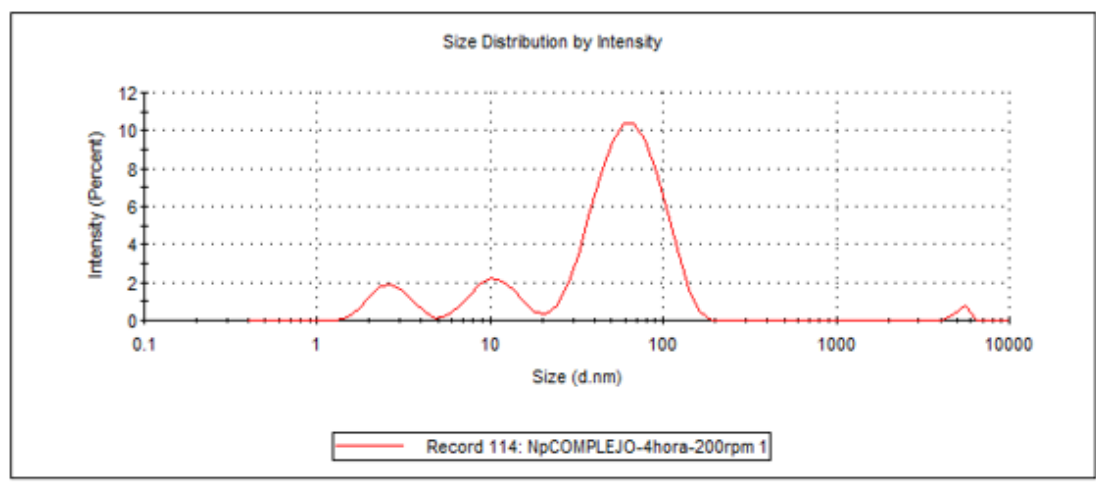

Fuente: Elaboración propia

Figura 3. Gráfica del histograma de los diámetros hidrodinámicos de las nanopartículas de plata por dispersión de luz dinámica (DLS)

En el histograma de los diámetros hidrodinámicos de las nanopartículas de plata, se observa una distribución polidispersa con tamaños de diámetro hidrodinámico alcanzado de 2,716 nm en un $8,7 \% ; 11,05 \mathrm{~nm}$ en un $11,8 \%$ y $67,63 \mathrm{~nm}$ en un $78,4 \%$; tamaño menor a $100 \mathrm{~nm}$, lo que ratifica la presencia de nanopartículas.

\section{Caracterización fisicoquímica de la arcilla}

A continuación, en la tabla 1 , están los resultados de las propiedades fisicoquímicas de la arcilla:

Tabla 1. Caracterización fisicoquímica de la arcilla

\begin{tabular}{cccccccc}
\hline Muestra & $\mathrm{pH}$ & $\begin{array}{c}\text { Sales } \\
\text { solubles } \\
\mathrm{g} / \%\end{array}$ & $\begin{array}{c}\text { Bases } \\
\text { intercambiables } \\
\%\end{array}$ & $\begin{array}{c}\text { CIC } \\
\text { (Capacidad de } \\
\text { intercambio de } \\
\text { cationes) } \\
\text { meq/100g }\end{array}$ & $\begin{array}{c}\text { Densidad } \\
\mathbf{g} / \mathrm{cm}^{3}\end{array}$ & $\begin{array}{c}\text { Humedad } \\
\%\end{array}$ & $\begin{array}{c}\text { Carbonatos } \\
\%\end{array}$ \\
\hline Arcilla & 5,6 & 0,06 & 27,84 & 16,60 & 1,595 & 3,608 & 0,00 \\
\hline
\end{tabular}

Fuente: Elaboración propia

Al caracterizar la arcilla, se encuentra que tiene un alto valor de bases intercambiables: $27,84 \%$, así como alto valor de capacidad de intercambio iónico (CIC) de 16,60 meq/100g, por lo que sería fácil que salgan estas bases o cationes, creando espacios libres.

\section{Obtención del filtro de arcilla-aserrín}

Los filtros arcilla-aserrín se obtuvieron mezclando arcilla pulverizada a malla 100 y aserrín de madera pulverizado a malla 100, en una proporción 2:1 con agua, se moldearon, se secaron y se llevaron a la temperatura de $800^{\circ} \mathrm{C}$, obteniéndose un cerámico duro de color rojizo. La 
porosidad es una propiedad importante que posee un filtro cerámico, ya que de esta depende el flujo de filtración de agua, esta porosidad se obtiene por el aserrín presente en la mezcla y se produce cuando el filtro es sometido a temperaturas superiores a los $800^{\circ} \mathrm{C}$.

\section{Caracterización morfológica por SEM-EDX de la cerámica obtenida}

A continuación se observa la microfotografía de la cerámica obtenida (figura 4):

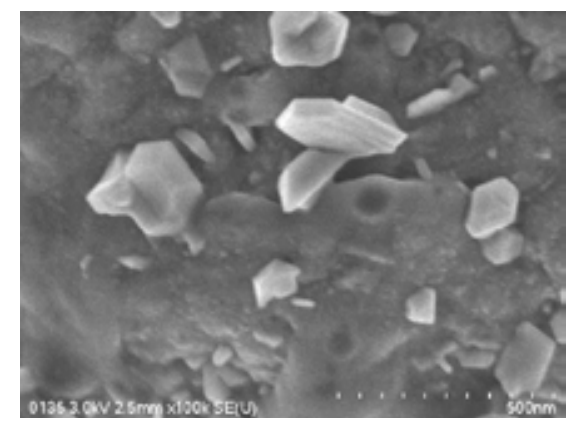

Fuente: Elaboración propia

Figura 4. Microfotografía de la cerámica

La microfotografía tomada por SEM presenta una magnificación de las superficies de 100 mil veces, se observa la estructura de la cerámica con cristalizaciones correspondientes a la morfología típica de la arcilla en tamaños de $50 \mathrm{~nm}$ a $200 \mathrm{~nm}$. Asimismo, se observa una fase no homogénea con depresiones pequeñas. La fase más dominante son superficies homogéneas.

Podemos observar también el espectro de los resultados del microanálisis elemental de la cerámica obtenida por EDX (figura 5):

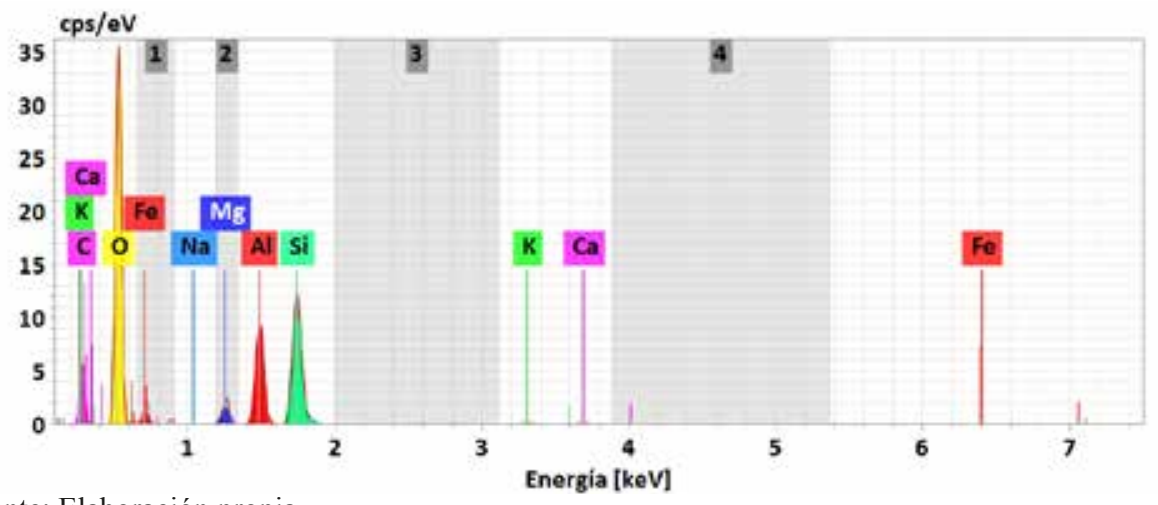

Fuente: Elaboración propia

Figura 5. Microanálisis elemental de la cerámica obtenida por EDX 
En este espectro se puede observar diferentes señales que muestran mayor proporción de oxígeno, silicio, seguida por el aluminio, carbono y hierro y en menor proporción como minoritarios: potasio, calcio, magnesio y sodio.

La composición general indica que existe una elevada cantidad de silicio y oxígeno (silicatos), cantidades menores de carbonato de calcio (calcita) y, probablemente, pequeñas fracciones de silicatos de aluminio y magnesio en forma de micas o feldespato y óxidos de hierro.

\section{Proceso de inmersión del filtro en la dispersión coloidal de carboximetilqui-tosano- nanopartículas de plata}

Se incorporaron las nanopartículas al filtro por el método de inmersión in situ, que consiste en sumergir el filtro en la solución de nanopartículas de plata-carboximetilquitosano durante 12 horas, se secaron a temperatura ambiente y con estos filtros se realizaron las pruebas.

\section{Caracterización morfológica por SEM-EDX del nanocomposito: cerámica - carboximetilquitosano-nanopartículas de plata}

A continuación se observa una microfotografía del nanocomposito: cerámica carboximetilquitosano-nanopartículas de plata (figura6):

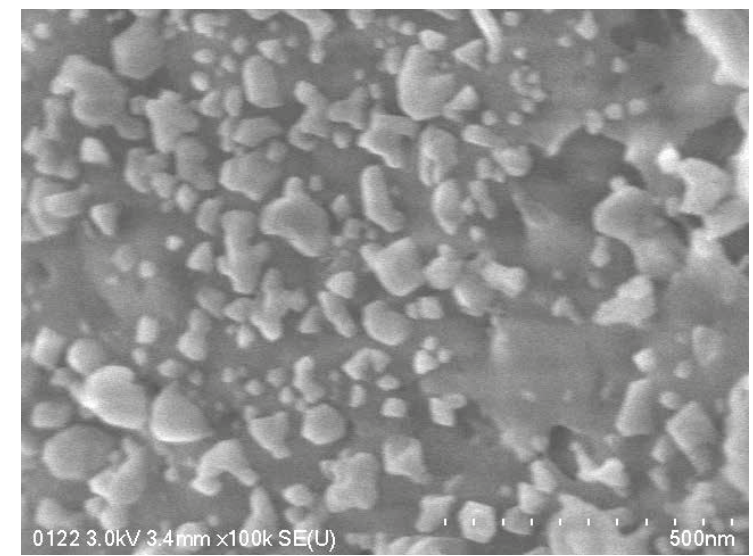

Fuente: Elaboración propia

Figura 6. Microfotografía del nanocomposito

La microfotografía tomada por SEM presenta una magnificación de las superficies de 100 mil veces, se observan cristalizaciones correspondientes a la morfología típica de la arcilla, con tamaños entre $20 \mathrm{~nm}$ y $100 \mathrm{~nm}$ y una capa que cubre las cristalizaciones, que correspondería al carboximetilquitosano con nanopartículas de plata.

Podemos observar también el espectro de los resultados del microanálisis elemental de la cerámica obtenida por EDX (figura 7): 


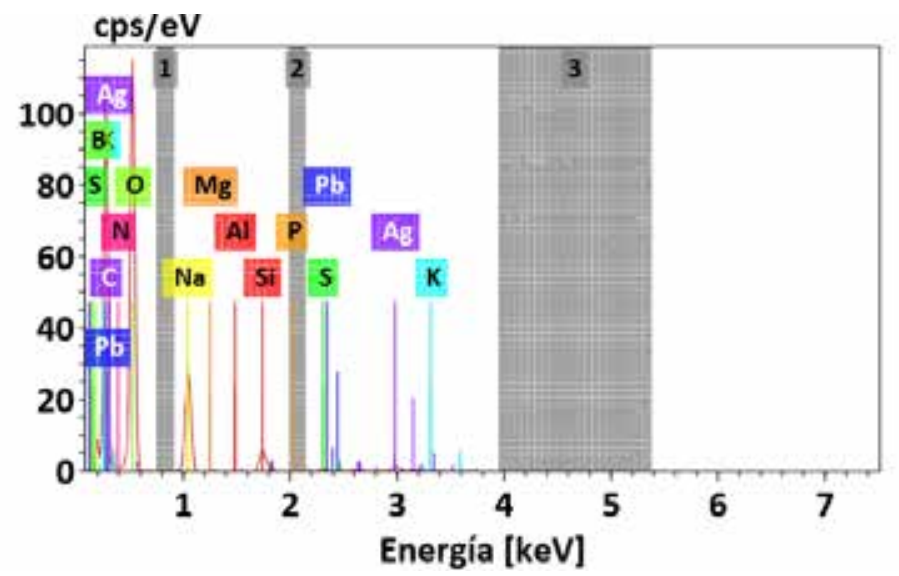

Fuente: Elaboración propia

Figura 7. Análisis EDX de la cerámica obtenida

En este espectro se puede observar diferentes señales que muestran mayor proporción de oxígeno, sodio, silicio, azufre seguida por el carbono, boro, nitrógeno, aluminio y en menor proporción, como minoritarios: potasio, magnesio y es notoria la presencia de plata por las nanopartículas de plata.

\section{Propiedades fisicoquímicas y bacteriológicas de las aguas en estudio antes y después} del filtrado.

Para realizar este paso, se filtraron las aguas en estudio con el filtro cerámico obtenido y se realizaron las siguientes pruebas de las fisicoquímicas: $\mathrm{pH}$, conductividad, turbiedad, aniones ${ }^{12}$; asimismo, de las propiedades bactericidas del nanocompósito, determinando el recuento de microorganismos: Numeración de coliformes totales, numeración de coliformes fecales, usando métodos estándar de la $\mathrm{AWWA}^{13}$. Las pruebas se realizaron con las muestras de agua antes y después del filtrado. A continuación se muestra la tabla 2 con los resultados obtenidos. 


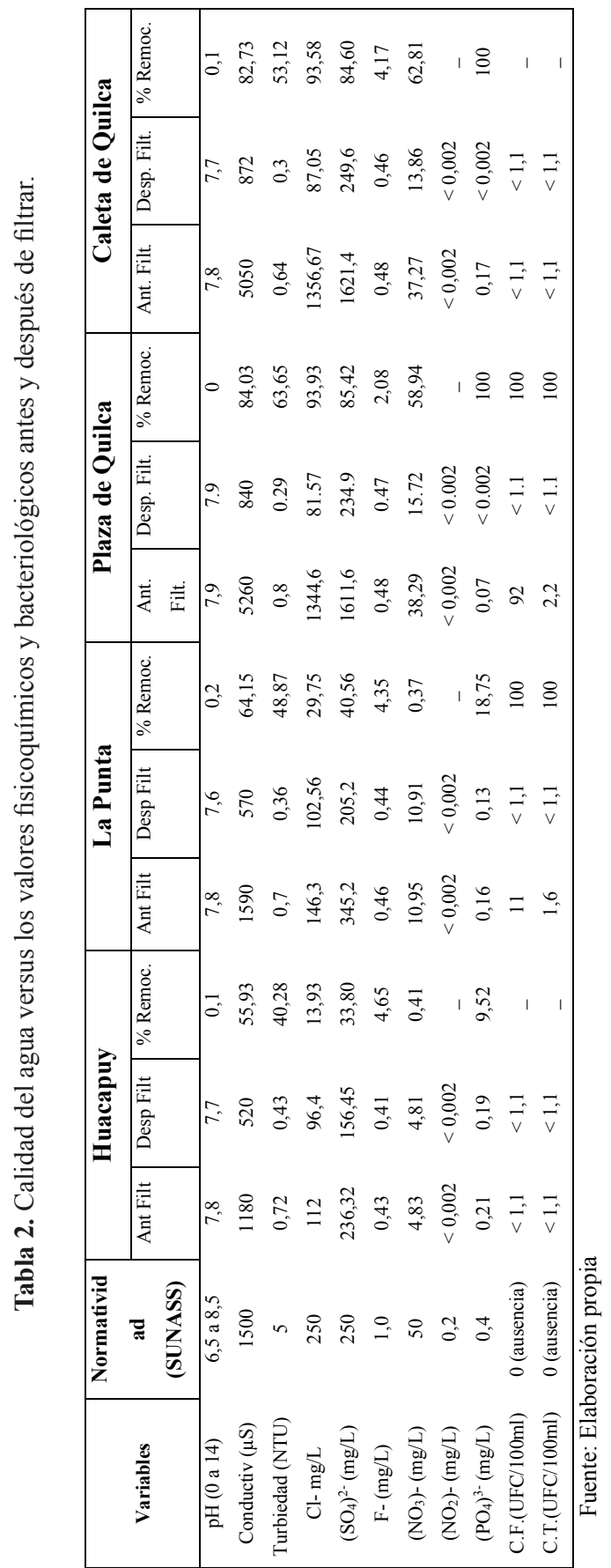


Para hacer el análisis de los resultados se hizo la tabla 3, donde se aprecian los valores antes de filtrar, los cuales sobrepasaron los valores permitidos por la Superintendencia Nacional de Servicios de Saneamiento (SUNASS) y que luego del filtrado disminuyeron hasta valores normales:

Tabla 3. Tabla Resumen de los valores fisicoquímicos y bacteriológicos que sobrepasaron los valores establecidos antes y después de filtrar.

\begin{tabular}{|c|c|c|c|c|c|c|c|c|c|}
\hline \multirow[t]{2}{*}{ Variables } & \multirow[t]{2}{*}{$\begin{array}{l}\text { Normatividad } \\
\text { (SUNASS) }\end{array}$} & \multicolumn{2}{|c|}{ Huacapuy } & \multicolumn{2}{|c|}{ La Punta } & \multicolumn{2}{|c|}{ Plaza de Quilca } & \multicolumn{2}{|c|}{$\begin{array}{l}\text { Caleta de } \\
\text { Quilca }\end{array}$} \\
\hline & & Ant. Filt. & Desp. Filt. & Ant. Filt. & $\begin{array}{l}\text { Desp. } \\
\text { Filt. }\end{array}$ & Ant. Filt. & Desp.Filt. & $\begin{array}{l}\text { Ant. } \\
\text { Filt. }\end{array}$ & Desp. Filt. \\
\hline Conductiv. $(\mu \mathrm{S})$ & 1500 & 1180 & 520 & 1590 & 570 & 5260 & 840 & 5050 & 872 \\
\hline $\mathrm{Cl}-\mathrm{mg} / \mathrm{L}$ & 250 & 112 & 96,4 & 146,3 & 102,56 & 1344,6 & 81,57 & 1356,67 & 87,05 \\
\hline$\left(\mathrm{SO}_{4}\right)^{2-}(\mathrm{mg} / \mathrm{L})$ & 250 & 236,32 & 156,45 & 345,2 & 205,2 & 1611,6 & 234,9 & 1621,4 & 246,6 \\
\hline C.F.(UFC/100ml) & 0 (ausencia) & $<1,1$ & $<1,1$ & 11 & $<1,1$ & 92 & $<1,1$ & $<1,1$ & $<1,1$ \\
\hline C.T.(UFC/100ml) & 0 (ausencia) & $<1,1$ & $<1,1$ & 1,6 & $<1,1$ & 2,2 & $<1,1$ & $<1,1$ & $<1,1$ \\
\hline
\end{tabular}

Fuente: Elaboración propia

En la tabla 3 se observa que, comparando los valores establecidos según (SUNASS) con los valores encontrados en los diferentes puntos de muestreo, se tiene que: las aguas después del filtrado aplicando el nanocompósito, se encontró que remueven en mayor proporción los siguientes valores: conductividad: 84,03 \% en La Plaza de Quilca, sulfatos 85,42 \% en La Plaza de Quilca, cloruros 93,93 \% en La Plaza de Quilca. Por otro lado, las bacterias coliformes fecales y coliformes totales se removieron en $100 \%$ en La Punta y en la Plaza de Quilca. No se encontraron bacterias coliformes en Huacapuy ni en la Caleta de Quilca. Por lo que se puede confirmar que los resultados tienen un porcentaje de remoción significativo en la eliminación de aniones y en cuanto a las bacterias coliformes totales y coliformes fecales en su totalidad.

\section{Funcionamiento del filtro}

El procedimiento se basa en la microfiltración a través de un material poroso, donde los poros de los filtros tienen un tamaño entre 0,6 y $0,3 \mu \mathrm{m}$, determinado aproximadamente por SEM. Según Van Der L.H. ${ }^{15}$ si el tamaño de poro sería de $0,1 \mu \mathrm{m}$ el filtro no necesitaría desinfectante para la eliminación de Escherichia coli que tiene un tamaño entre 0,5 a $1 \mu \mathrm{m}$.

Por otro lado, según Ludeña J.14, la presencia de nanopartículas de plata, cerca de un virus, hongo, bacteria o cualquier otro microbio patógeno unicelular, incapacita la enzima del metabolismo del oxígeno y en pocos minutos el microbio patógeno se sofoca, muere y es eliminado del cuerpo por los sistemas inmunológico y linfático.

Vidal S. ${ }^{10}$ indica que si la plata se une a la membrana celular de las bacterias, estas incrementan su tamaño y contenido citoplasmático y presentan anormalidades que resultan en lisis celulares y muerte. 
Según los resultados obtenidos de Lantagne, los filtros a base de arcilla y aserrín forman poros de 0,6 a $3 \mu \mathrm{m}$ lo cual se determinó por SEM y se eliminan microorganismos como parásitos entre ellos Giardia y Cryptosporidium que oscilan en 5 - $7 \mu \mathrm{m}$ y $5 \mu \mathrm{m}$, respectivamente, en un $99,99 \%$ pero no un $100 \%$ por lo que es necesario la impregnación de la plata coloidal ya que remueve totalmente a las bacterias.

\section{CONCLUSIONES}

Al aplicar a las muestras de aguas en estudio, el sistema filtrante a base del nanocompósito arcilla - carboximetilquitosano - nanopartículas de plata, se mejoró la calidad de las aguas contaminadas con bacterias y sustancias químicas, produciendo agua apta para el consumo humano, por lo que se desarrolla un sistema filtrante de bajo costo, tecnología simple, ecológicamente aceptable y económicamente accesible a las poblaciones rurales de bajos recursos.

Después del filtrado de las aguas usando el nanocompósito, se encontró que remueven en mayor proporción los siguientes valores: conductividad: 84,03 \% en La Plaza de Quilca, sulfatos 85,42 \% en La Plaza de Quilca, cloruros 93,93 \% en La Plaza de Quilca. Por otro lado, las bacterias coliformes fecales y coliformes totales se removieron en $100 \%$ en La Punta y en la Plaza de Quilca. No se encontraron bacterias coliformes en Huacapuy ni en la Caleta de Quilca. Por lo que se puede confirmar que los resultados tienen un porcentaje de remoción significativo en la eliminación de aniones y en cuanto a las bacterias coliformes totales y coliformes fecales en su totalidad.

\section{AGRADECIMIENTO}

A la Universidad Nacional de San Agustín de Arequipa, UNSA, por el financiamiento del proyecto de investigación según Contrato de Subvención Nº6-2017-UNSA.

\section{REFERENCIAS BIBLIOGRÁFICAS}

1. Díaz del Castillo F. Introducción a los Nanomateriales. [Internet]. México: Facultad de Estudios Superiores Cuautitlán (UNAM); 2012. [Citado 11 abril 2018]. Disponible en: http://olimpia.cuautitlan2.unam.mx/pagina_ingenieria/mecanica/mat $/ \mathrm{mat}$ _mec/m6/ Introduccion $\% 20 \mathrm{a} \% 2010 \mathrm{0} \% 20$ nanomateriales.pdf

2. Almansi F. Mejorando la provisión de servicios de agua, saneamiento e higiene para las comunidades urbanas de bajos recursos en América Latina: Caso Guayaquil. Medellin: Programa de Agua y Saneamiento para América Latina - Banco Mundial (WSP-BM); 2006.

3. Zhang Y, Peng H, Huang W, Zhou Y, Yan D. Facile preparation and characterization of highly antimicrobial colloid Ag or Au nanoparticles. J Colloid Interface Sci. 2008; 325(2):371-376. 
4. Pérez A, Díaz J, González G. Estudio comparativo de dos sistemas de filtración casera para el tratamiento de agua para consumo humano. Ingenium. 2014; 8(22):1-20

5. Garrido L, Albano M. Procesamiento de cerámicos porosos de zirconia por consolidación directa con almidón. CONAMET-SAM, 2008: Santiago de Chile, Chile.

6. Weepiu J. Evaluación de los Filtros Cerámicos para Mejorar la calidad del Agua para consumo humano del Sector San Mateo, Moyobamba.[Tesis para obtener el título de Ingeniero Sanitario]. Moyobamba: Universidad Nacional de San Martín, Perú. 2016.

7. Balu A. Nanopartículas soportadas sobre materiales porosos para la sintesis de productos de alto valor añadido.[Tesis doctoral] Córdoba: Universidad de Córdova, Argentina; 2012.

8. Juárez H, Contreras J, García V, Herrera C. Sistematización del proceso de filtros potabilizadores. Guatemala; 2011.

9. Monge M. Nanopartículas de plata: métodos de síntesis en disolución y propiedades bactericidas. An Quím. 2009; 105(1): 33-41

10. Vidal S. Evaluación de la efectividad de la efectividad del filtro a base de arcilla y plata coloidal en la potabilización del agua, medidas por pruebas fisicoquímicas y microbiológicas. [Tesis] Pereira, Colombia: Universidad Tecnológica de Pereira; 2010.

11. Tarazona A, Peña D. Estudio de la remoción de coliformes en aguas naturales utilizando un filtro tipo cartucho empacado con nanocompósitos de fibras de fique con nanopartículas de plata. [Tesis]. Bucaramanga, Colombia; Universidad Industrial de Santander; 2011.

12. APHA-AWWA-WEF (2005) Standard Methods for the Examination of Water and Wastewater, 2120 B: Visual comparation method. 21th Edition. Washington DC: American Public Health Association; 2005.

13. Balcázar C. Agua y saneamiento para las zonas Programa de Agua y Saneamiento marginales urbanas de América Latina. Memoria del taller internacional. Medellín, Colombia; 2008.

14. Ludeña J, Tinoco F. Formulación de Pasta Roja para la elaboración de un filtro cerámico purificador de agua y verificación de su efectividad filtrante. [Tesis]. Loja, Ecuador: Universidad Técnica Particular de Loja; 2010.

15. Van Der LH, Van Halem D, Smeets PW, Soppe AI, Kroesbergen J, Wubbels FG. Bacteria and virus removal effectiveness of ceramic pot filters with different silver applications in a long term experiment. Water Res. 2014; 51: 47-54. 